\title{
Molecular pathology of the cancer cell
}

\author{
JOHN PAUL AND IVOR HICKEY \\ From the Beatson Institute for Cancer Research, Glasgow
}

The recognition that a common feature of all cancer cells is a disorganization of the stringent controls involved in normal cell differentiation has been so obvious for such a long time that the statement assumes the character of a well worn cliché. Perhaps for this reason the impression is widespread that progress in understanding these cellular control mechanisms is being made only very slowly, but nothing could be further from the truth. Within the past decade dramatic advances have been made in understanding cellular function. These have provided a substantial framework on which it is now possible to erect models which can be tested by incisive experimentation. Most of these advances have emerged directly from the fundamental advances which were made in our understanding of biological processes as a result of the impact of molecular biology.

Molecular biology implies the interpretation of biological phenomena in molecular terms. A large component of molecular biology is, therefore, biochemistry but molecular biology also exploits a wide range of associated disciplines such as biophysics and genetics. Much of the classical work of molecular biology had to do with the elucidation of the details of protein synthesis and its control; the 'central dogma' of the discipline lays down the principle that genetic information for proteins is encoded in DNA, transcribed from it into messenger RNA, and then translated from the messenger RNA, by a machinery employing ribosomes, transfers RNA and other factors to give proteins. Most of our basic understanding of these processes has been gained from studies with microorganisms but, within the past decade, there has been an increasing accumulation of information about the molecular biology of eukaryotic cells, particularly about protein synthesis. This has made it possible to recognize abnormalities of these mechanisms and it is the study of these which is defined as molecular pathology.

Molecular pathology is particularly relevant to the study of cancer because there is now ample evidence that the lesions which result in the formation of a cancer cell are very often, and possibly invariably, associated with abnormalities of nucleic acid and/or protein synthesis. In this communication some of these will be briefly discussed.

\section{Abnormal Protein Synthesis as a Feature of Cancer Cells}

Differentiated cells are distinguished from other cells in the same organism by, inter alia, characteristic complements of proteins; certain proteins, such as haemoglobin, are absolutely characteristic of certain cell types. It seems likely that in the course of normal differentiation cells of one type never make the products characteristic of another type. However, it has been clearly recognized for some years and, indeed, forms the basis of the deletion theory expounded by Potter (1958), that during the development of some tumours specific enzyme activities are lost. This phenomenon has been studied in considerable detail during the development of hepatomas. Some particularly interesting observations from Potter's and other laboratories (Pitot, Peraino, Morse, and Potter, 1964) have demonstrated that in minimum deviation hepatomas, in which almost all the enzymes of normal liver may be observed, the mechanisms involved in the control of enzyme activity may be disturbed (table I). Greenstein (1954), who did much of the pioneering work in this field, demonstrated that, in general, the spectrum of proteins eventually becomes very similar in a great variety of tumours, in contrast to the situation in normal tissues.

On the other hand, it is common for cancer cells to synthesize proteins which they might not be expected to produce on the basis of the presumed tissue of origin. Table II provides a brief summary of some of the proteins formed in tumours arising from tissues which do not normally make them or, alternatively, make them in undetectable amounts. Para-endocrine cancer syndromes have been recognized clinically for many years (see Goodall, 1969). 


\begin{tabular}{|c|c|c|c|}
\hline \multirow[t]{2}{*}{ Enzyme } & \multirow[t]{2}{*}{ Inducer or Repressor } & \multicolumn{2}{|l|}{ Effect on } \\
\hline & & Normal Liver & Hepatoma \\
\hline Tryptophan pyrollase & Tryptophan & Increase & No effect or abnormal \\
\hline Tyrosine transaminase & Cortisone & Increase & Enhanced response \\
\hline $\begin{array}{l}\text { Glucose-6-phosphate } \\
\text { dehydrogenase }\end{array}$ & Dietary carbohydrate & Increase & No effect \\
\hline $\begin{array}{l}\text { Threonine dehydrase } \\
+ \text { ornithine transaminase }\end{array}$ & Dietary protein & Increase & No effect or abnormal \\
\hline $\begin{array}{l}\text { Cholesterol biosynthesis } \\
\text { Threonine dehydrase } \\
\text { + ornithine transaminase }\end{array}$ & $\begin{array}{l}\text { Dietary cholesterol } \\
\text { Dietary glucose }\end{array}$ & $\begin{array}{l}\text { Decrease } \\
\text { Decrease }\end{array}$ & $\begin{array}{l}\text { No effect } \\
\text { No effect }\end{array}$ \\
\hline
\end{tabular}

Table I Modified control mechanisms in hepatomas

\begin{tabular}{|c|c|}
\hline $\begin{array}{l}\text { Abnormal Protein } \\
\text { Formed or Presumed } \\
\text { Formed }\end{array}$ & Tumour \\
\hline Erythropoietin & $\begin{array}{l}\text { Cerebellar haemangioblastoma, uterine } \\
\text { myofibroma, hepatoma, melanoma }\end{array}$ \\
\hline АCTH & Bronchogenic lung cancer, thymoma \\
\hline 'Insulin-like’ & Mesenchymomas \\
\hline Parathormone & Bronchogenic lung cancer \\
\hline Thyrotrophin & Trophoblastic tumours \\
\hline $\begin{array}{l}\text { Carcinoembryonic } \\
\text { antigen }\end{array}$ & Carcinoma of colon \\
\hline Alpha-fetoprotein & Hepatocellular cancer \\
\hline
\end{tabular}

Table II Abnormal proteins synthesized in association with some human tumours

Besides the examples quoted, evidence for abnormal synthesis of antidiuretic hormone, melanin-stimulating hormone, and gonadatrophic hormone have been reported. Some tumours may even secrete several different hormones. For example, thyroid tumours causing Cushing's syndrome have been described (Dyson, 1959; Riggs and Sprague, 1961) and oat-cell carcinomas have been reported to secrete all the pituitary hormones. The inference that the synthesis of, for example, ACTH by oat-cell carcinomas represents a disturbance of a cellular control mechanism is reinforced by the observation that dexamethasone does not cause a depression of urinary 17hydroxycorticoid excretion in this syndrome whereas in Cushing's disease there is a striking response to it (Liddle, 1960). There are many other observations of this kind: for example, hypercalcaemia associated with some kinds of malignant disease is often reversed by cortisone whereas that of primary hyperparathyroidism is not. Particular interest has, of course, also been attached to the discovery in the blood of cancer patients of many antigens which are normally detectable only in the embryo (Abelev, 1971; Laurence and Neville, 1972). These observations all point to derepression of genetic functions which are normally not expressed in differentiated cells. To the molecular biologist this is of particular interest because he can test models based on this hypothesis.

With our current understanding of eukaryotic molecular biology, it is possible to postulate likely sites of lesions in the metabolic machinery of the cell which could give rise to disturbed patterns of protein synthesis (fig 1). Lesions can occur during the replication of DNA (fig 1,1$)$ and here there are two major possibilities. The first is mutation. Chemical carcinogens have been postulated to be mutagens, and, indeed, there is a considerable amount of recent evidence which shows a close correlation between carcinogenicity and mutagenicity of the active derivatives of carcinogens. Many carcinogens such as the nitrosamines react vigorously with DNA to produce changes in it (Magee and Barnes, 1967). It has been postulated, therefore, that the nitrosamines and possibly other chemical carcinogens may interact directly with DNA. Allison (1969), on the other hand, has suggested that many carcinogens could have a common mode of action by disrupting lysosomes and releasing nucleases into the cell sap. If nucleases reach the nucleus, it can be shown experimentally that they produce chromosome breaks. According to both of these hypotheses, the

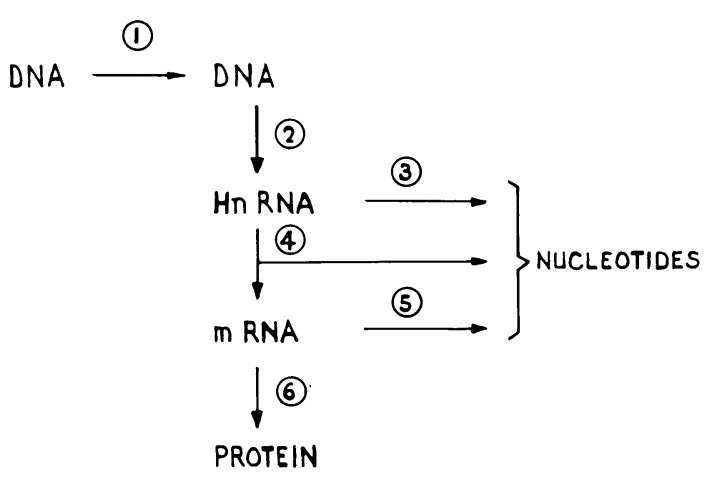

Fig 1 Possible sites of lesions in the proteinsynthesizing machinery of the cell: (I) DNA replication; (2) transcription of DNA into $H n R N A$; (4) processing of $H n R N A$ to form $M R N A$; with partial degradation; (3) and (5) degradation of $R N A$; (6) translation of information from $R N A$ into protein. 
abnormalities of protein synthesis in cancer cells result from mutations. Point-mutations affecting single proteins, such as enzymes, would be unlikely to produce the rather gross abnormalities seen in cancer cells (unless they occurred in special genes involved in regulating some general functions of the cell). It is, therefore, necessary to postulate mutations sufficiently large to affect several functions, eg, large deletions. However, not all the data are easy to explain on the basis of somatic mutations; in particular, it is difficult to reconcile the rather stereotyped patterns of emergence of many cancers with random events.

An entirely different hypothesis concerning the production of DNA abnormalities is based on the viral theory of carcinogenesis. This proposes that alterations occur in the genome by insertion of viral DNA. The act of insertion could itself produce mutations; alternatively, the viral DNA could give rise to abnormal RNA as discussed later.

The second possible site of lesions is during the transcription of DNA into RNA (fig 1, 2). There is excellent evidence that, in eukaryotic cells, only a small fraction of the genome is transcribed at any one time and that in cells of different types different genes are transcribed. There must, therefore, exist an effective mechanism for the regulation of gene activity in normal eukaryotic cells and it is possible that this is disturbed in cancer cells. In eukaryotic cells, the product of transcription is a high molecular weight RNA called HnRNA - heterogeneous nuclear RNA. This kind of RNA is usually found only in the nucleus and much of it is degraded there. Some may be degraded completely (fig 1,3 ) but other molecules are 'processed', that is, part of the molecule is degraded and the remainder forms messenger RNA (fig 1, 4). A balance between processing and degradation may be involved in determining whether some messengers are eventually translated or not. Messenger RNA which reaches the cytoplasm is degraded more or less rapidly (fig 1,5 ) but is usually translated before it is degraded (fig 1,6). There is very good evidence for special mechanisms which control the translation of messenger RNA.
Again, therefore, the balance between degradation of messenger RNA and its translation may determine the nature and amount of proteins synthesized.

\section{Abnormalities of RNA in Cancer Cells}

The fact that at least some of the changes in cancer occur at the transcriptional level is strongly suggested by observations that the kinds of RNA present in cancer cells are often different from the kinds of RNA in normal cells. These comparisons are commonly carried out by the technique of RNA/ DNA hybridization, sometimes referred to as 'molecular matching'. The principle involved in these studies is that RNA transcribed from a given DNA template is uniquely complementary to that portion of DNA from which it was transcribed. By a simple procedure the separated strands of DNA and RNA can be caused to associate to form a double-stranded structure (provided they have the requisite degree of complementarity) and this double-stranded structure, or hybrid, can be isolated and measured. It is thus possible, for example, to determine whether a given kind of RNA could have been transcribed from a given DNA or not. It is also possible to determine whether two samples of RNA are similar by observing whether they compete for complementary sites on the same DNA. For example, two RNAs can be distinguished by labelling one with a radioisotope and determining whether increasing the amount of the other reduces the hybridization of the radioactive species.

In many studies of this kind evidence has been obtained for differences between the RNA of tumour and normal cells (table III). For example, Drews, Brawerman, and Morris (1968) reported a deficiency in some RNA classes in hepatoma cells as compared with normal rat liver cells. Chiarugi (1969) compared rat liver, Yoshida ascites hepatoma cells, and Morris 132 hepatoma cells and found that the RNA spectra in these all differed. A similar conclusion was drawn by Church, Luther, and McCarthy (1969) from studies on mouse liver and the Taper hepatoma and also by Mendecki, Minc,

\begin{tabular}{lll}
\hline Tissues Compared & Finding & Authors \\
\hline $\begin{array}{l}\text { Rat liver v hepatoma } \\
\text { Rat liver v Yoshida hepatoma and Morris 5132 } \\
\text { hepatoma }\end{array}$ & $\begin{array}{l}\text { Some classes of RNA deficient in hepatoma } \\
\text { All RNAs different }\end{array}$ & $\begin{array}{l}\text { Drews } \text { et al (1968) } \\
\text { Chiargui (1969) }\end{array}$ \\
Mouse liver v Taper hepatoma & $\begin{array}{l}\text { Greater diversity of RNA molecules in } \\
\text { the hepatoma } \\
\text { Greater diversity of RNA molecules in }\end{array}$ & Church et al (1969) \\
Human lymphocytes v CLL lymphocytes & $\begin{array}{l}\text { the hepatoma } \\
\text { Additional RNA molecules in tumour cells } \\
\text { Normal mammary tissue v carcinoma of breast } \\
\text { Additional RNA molecules in tumour cells }\end{array}$ & $\begin{array}{l}\text { Neiman and Henry (1969) } \\
\text { Turkington and Self (1970) }\end{array}$
\end{tabular}

Table III Abnormalties of RNA in tumour cells 


\begin{tabular}{lll}
\hline $\begin{array}{l}\text { Source of } \\
\text { Competing } R N A\end{array}$ & $\begin{array}{l}\text { Percentage Competition by } \\
\text { Individual Samples }\end{array}$ & Mean \pm SD \\
\hline Chronic lymphatic leukaemic lymphocytes & $94,91,97,90,89,98$ & $94 \pm 3.9$ \\
Normal lymphocytes & $75,75,75,69,72$ & $73 \pm 2 \cdot 4$ \\
\hline
\end{tabular}

Table IV Competition between RNA from CLL lymphocytes and RNA of the same kind from several patients or $R N A$ from normal lymphocytes ${ }^{1}$

${ }^{1}$ Data from Neiman and Henry (1969).

and Chorąży (1969), again studying rat hepatomas. Nieman and Henry (1969) compared normal lymphocytes and chronic lymphatic leukaemia lymphocytes. Again, these showed consistent differences (table IV). Turkington and Self (1970) similarly reported differences between the RNA from mammary tissue and breast cancer.

Work in recent years (Paul and Gilmour, 1966, 1968) has shown that specificity of transcription resides in chromatin and persists even after its isolation. A few studies have been undertaken which seem to show that the pattern of transcription from chromatin from tumour cells differs from that of normal cells (Jacob and Busch, 1967). These latter studies were perhaps a little premature but the techniques for undertaking meaningful studies of this nature are now available.

\section{Nature of Abnormal RNAs}

Many RNA viruses have been implicated in animal tumours, and since the diseases produced by them often bear striking similarities to human malignant disease, they have attracted particular attention of late. Special interest has been aroused by the discovery that probably all RNA tumour viruses contain reverse transcriptase, an enzyme which is capable of forming a DNA copy from viral RNA. Within the past two years this has had a profound influence on our thinking about viral carcino- genesis. Initially there was considerable enthusiasm for the use of reverse transcriptase as a diagnostic test for tumour viruses. This gave rise to some unfortunately misleading findings. More recently, reverse transcriptase activity has been exploited in another way and has proved to be a most powerful tool. It is currently postulated that, at some stage in their growth cycles, RNA tumour viruses are copied by reverse transcriptase to form DNA copies which may or may not be integrated into the host genomes (fig 2). Subsequently, the DNA may be transcribed (and possibly cotranscribed with host DNA) to form RNA molecules containing viral RNA. A corollary of this hypothesis is that cells which have been transformed by a virus should contain RNA of a viral type. This can be tested very precisely because reverse transcriptase can be used to synthesize a complementary DNA of high specific activity which, in turn, can be used as an extremely sensitive probe for the presence of viral RNA. This tool has been exploited, particularly by Spiegelman's group, in a search for possible viruses in human tumours (Spiegelman, Axel, and Schlom, 1972; Axel, Schlom, and Spiegelman, 1972; Kufe, Hehlmann, and Spiegelman, 1972; Hehlmann, Kufe, and Spiegelman, 1972a,b). Among the most striking claims which this group have made is that in human mammary carcinomas, RNA can be demonstrated which is apparently identical with mouse mammary tumour virus RNA (table V).

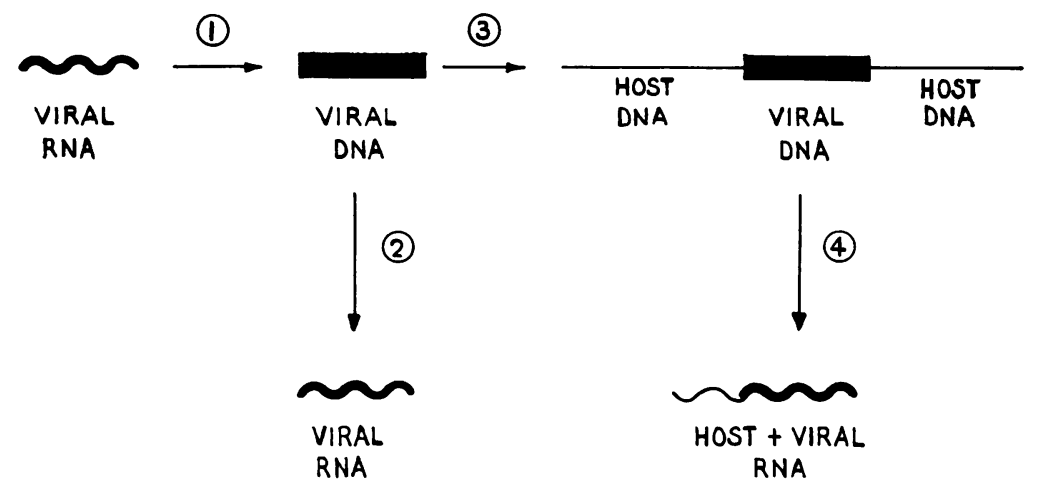

Fig 2 Possible fates of viral genetic information. (1) Transcription of viral RNA into $D N A$ by reverse transcriptase; (2) transcription of viral DNA into $R N A ;(3)$ integration of viral DNA into host genome; (4) cotranscription of host and integrated vira DNA. 


\begin{tabular}{|c|c|c|c|}
\hline Tissue Source of RNA & $\begin{array}{l}\text { Relative Hybridization Values in } \\
\text { Individual Samples }\end{array}$ & $M e a n \pm S D$ & Fraction $>3$ \\
\hline $\begin{array}{l}\text { Normal breast } \\
\text { Malignant adenocarcinoma }\end{array}$ & $\begin{array}{l}1 \cdot 7,1 \cdot 4,1 \cdot 1,1 \cdot 4 \\
3 \cdot 6,5 \cdot 2,0 \cdot 7,2 \cdot 4,4 \cdot 0,5 \cdot 5,4 \cdot 7,4 \cdot 7,24 \cdot 4, \\
5 \cdot 4,2 \cdot 2,1 \cdot 4,4 \cdot 7,3 \cdot 7,1 \cdot 5,5 \cdot 7,15 \cdot 7,2 \cdot 9,2 \cdot 6, \\
0 \cdot 7,6 \cdot 4,4 \cdot 6,3 \cdot 6,1 \cdot 0,4 \cdot 3,6 \cdot 7,0 \cdot 5,3 \cdot 5\end{array}$ & $\begin{array}{l}1.4 \pm 0.2 \\
4.73 \pm 4.73\end{array}$ & $\begin{array}{l}0 / 4 \\
18 / 28\end{array}$ \\
\hline Medullary carcinoma & $5 \cdot 2$ & $5 \cdot 2$ & $1 / 1$ \\
\hline Fibrocystic disease & $0 \cdot 8,0 \cdot 9,1 \cdot 0,0 \cdot 4,1 \cdot 8,0 \cdot 8,0 \cdot 8$ & $0.9 \pm 0.4$ & $0 / 7$ \\
\hline Gynaecomastia & $1 \cdot 3$ & $1 \cdot 3$ & $0 / 1$ \\
\hline Monocytic leukaemia & $1 \cdot 0,0.9$ & 0.95 & $0 / 2$ \\
\hline Acute myelocytic leukaemia & $1 \cdot 7,0 \cdot 0$ & 0.85 & $0 / 2$ \\
\hline Osteogenic sarcoma & 0.3 & $0 \cdot 3$ & $0 / 1$ \\
\hline Liposarcoma & 0.0 & 0.0 & $0 / 1$ \\
\hline Human placenta & $1 \cdot 0$ & $1 \cdot 0$ & $0 / 1$ \\
\hline Human liver & $1 \cdot 6$ & $1 \cdot 6$ & $0 / 1$ \\
\hline Human intestine & $1 \cdot 6$ & $1 \cdot 6$ & $0 / 1$ \\
\hline
\end{tabular}

Table V Extent of hybridization of DNA copied from mouse mammary tumour virus ${ }^{1}$

'Data from Axel et al (1972).

The discovery that RNA tumour viruses could be transcribed into DNA, together with the implication that this could in turn be integrated into the host genome, has led Huebner and Todaro (1969) to refurbish the 'oncogene hypothesis'. This hypothesis states that an 'oncogene' exists normally in a dormant state in the genome. When this gene is activated, cancer ensues. Huebner and Todaro postulate that the DNA copy from an RNA tumour virus could become integrated into DNA in the germ cell line and could then be inherited in Mendelian fashion to be activated some time in the future if an appropriate stimulus were received by the cell.

In cells transformed with DNA tumour viruses, such as polyoma and SV40 viruses, it has been clearly shown that viral DNA is incorporated into the host genome and that, in transformed cells, it is subsequently transcribed, with the result that RNA complementary to viral DNA can be found in transformed cells even when free virus is not present (Winocour, 1971). In unaffected cells, such an RNA is, of course, invariably absent. The function of the new RNA is not clearly established although it seems likely that at least some of it acts as messenger RNA for the synthesis of viral specific proteins such as $T$ antigens.

Some cells which have been transformed by RNA viruses similarly contain very little detectable virus. In other instances a considerable number of virus particles is produced and these may contribute to the RNA spectrum within the cell. However, using the hybridization methods for assay of RNA, it would not be expected that either viral RNA or RNA transcribed from a DNA virus would hybridize with DNA from normal cells. Hence, differences in RNAs demonstrated by hybridization of RNA to normal DNA are not likely to be due to this cause. This kind of observation has compelled the specula- tion that many of the differences in RNA populations in transformed cells as compared with normal ones are due to different genes being switched on in them, ie, the pattern of transcription is changed. In theory this could be due to the production of abnormal signals, for example, from viruses or as a result of mutation, or, alternatively, it could be due to some malfunction of the switching mechanism within the cell without any other cause. However, 'confused differentiation', ie, the simultaneous appearance in one cell of unique characteristics of different cells, is probably never seen except in cancer cells. There is insufficient experimental evidence to be categorical about this but some quite detailed studies in the phenomenon of 'determination' in insects seems to support the contention quite strongly (Hadorn, 1965). Hence, a simple spontaneous disturbance of regulation within cells seems unlikely and it seems much more probable that in cancer there are specific molecular lesions which produce interference with normal control circuits. An implication of this is that in viral carcinogenesis viral and host information may interact quite intimately. This suggestion has been made repeatedly in tumour virology.

Recent studies by us at the Beatson Institute point to a rather unexpected interaction between an RNA virus and the host cell in which it grows which could help us to understand such relationships. These studies have been conducted with an erythroleukaemic mouse cell line produced by the Friend virus. As first shown by Friend and her colleagues (Friend, Scher, Holland, and Sato, 1971) haemoglobin synthesis can be induced when these cells are treated with dimethylsulphoxide (DMSO) (fig 3). Following this treatment the fraction of the total cell population which synthesizes haemoglobin is never $100 \%$ but is usually of the order of $60 \%$ to 


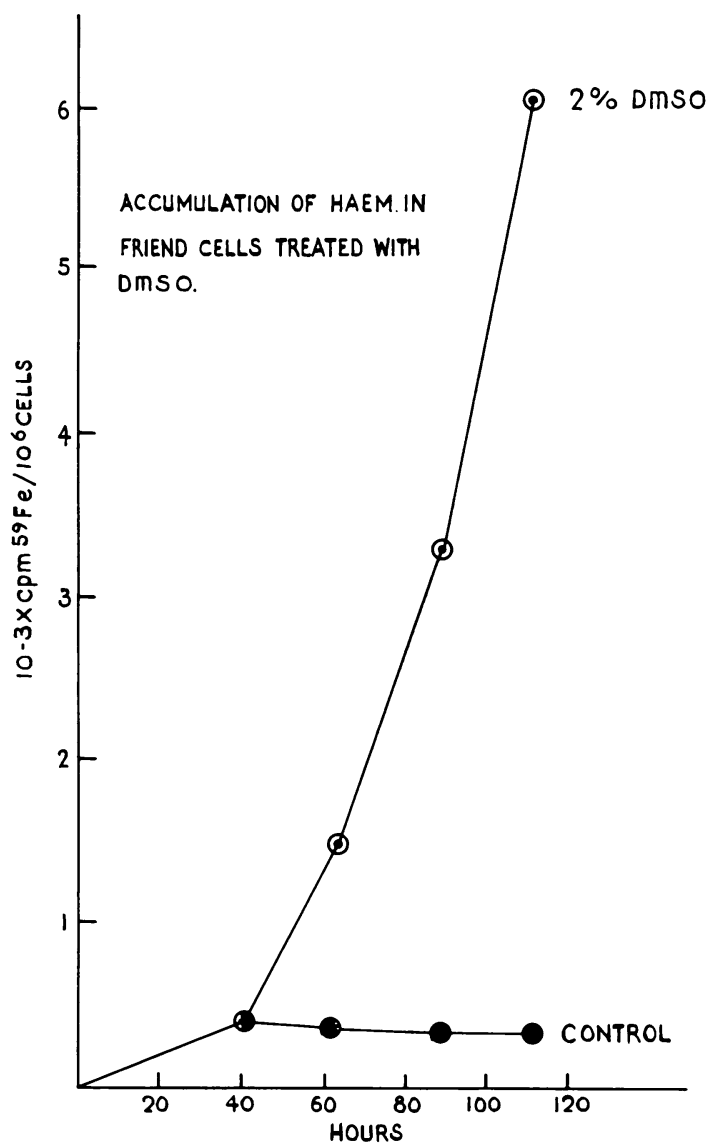

Fig 3 Accumulation of haem in untreated Friend cells (๑-๑) and in cells treated with dimethylsulphoxide $(\odot-\odot)$.

$80 \%$ in these experiments. The first question we asked was whether the fact that only a fraction of the cells formed haemoglobin was due to there being inducible and non-inducible subpopulations. This was tested by a fluctuation test; as is shown in fig 4 all of 55 clones tested behaved in much the same way in that a fraction of the population formed haemoglobin in response to dimethylsulphoxide. This excludes the possibility that the fractional response is due to simple segregation.

We have been able to obtain an inducible and a non-inducible line of these cells and this has made it possible to do some simple genetic studies. When hybrid cells were formed between inducible and non-inducible lines, the fraction of these cells which synthesized haemoglobin fell between the figures obtained for the parent cell lines (table VI). These findings are difficult to reconcile with a simple

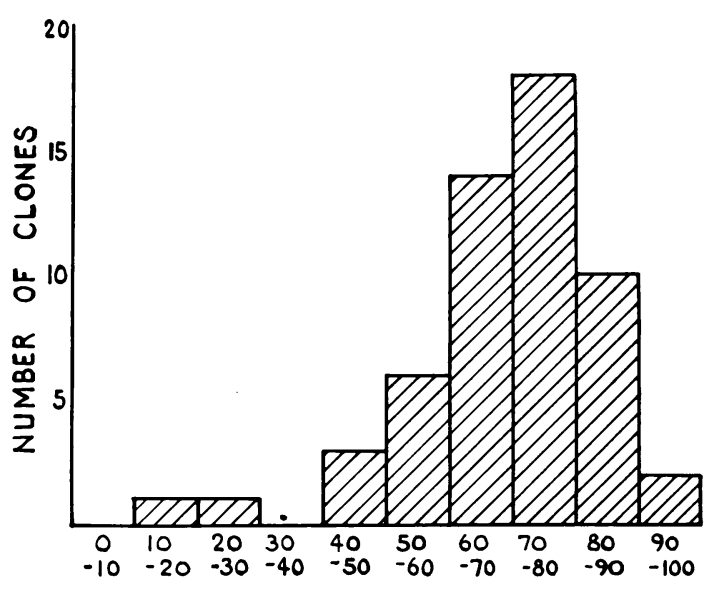

Fig. 4 The distribution of benzidine-staining cells in 55 individual clones of Friend cells following treatment with dimethylsulphoxide.

Mendelian segregation of chromosomal characteristics. There are two alternative explanations. Classically the kinds of results obtained in these experiments could be explained by inheritance of a nonchromosomal factor, ie, an episome such as a virus. The other possibility is, of course, that some unknown regulatory mechanism involved in cytodifferentiation might be responsible for this behaviour. There is some independent information which suggests that viruses of this group may react with the host in a specific way. The leukaemia induced in mice by the Friend virus is typically an anaemic erythroblastic leukaemia but a closely related virus described by Mirand produces a polycythaemic erythroid leukaemia. Unfortunately, the biology of these viruses is very little understood, but, taken together, these pieces of evidence might suggest that this virus produces a signal which is in some way involved in the regulation of haemoglobin synthesis. Should this turn out to be the case, it might indicate an

\begin{tabular}{lll}
\hline Clone & $\begin{array}{l}\text { Percentage Cells } \\
\text { Benzidine }+\end{array}$ & $\begin{array}{l}\text { Response Relative to } \\
707 \text { Cell }\end{array}$ \\
\hline 1 & 62 & $0 \cdot 89$ \\
2 & 21 & $0 \cdot 30$ \\
3 & 32 & $0 \cdot 46$ \\
5 & 47 & $0 \cdot 67$ \\
6 & 27 & $0 \cdot 39$ \\
7 & 64 & $0 \cdot 91$ \\
8 & 24 & $0 \cdot 34$ \\
Uncloned line & 59 & $0 \cdot 84$ \\
\hline
\end{tabular}

Table VI Stimulation by DMSO of hybrid clones formed between $F_{\mathrm{w}}$ (uninducible) and 707 (inducible) Friend cells 
interesting close relationship between tumour viruses and host cells. Since a great deal is known about haemoglobin synthesis, a system of this kind could be useful in elucidating these relationships.

This work was supported by grants from the Medical Research Council and the Cancer Research Campaign.

\section{References}

Abelev, G. I. (1971). Alpha-fetoprotein in ontogenesis and its association with malignant tumors. Advanc. Cancer res., 14, 295-358.

Allison, A. C. (1969). Lysosomes and cancer. In Lysosomes in Biology and Pathology, edited by J. T. Dingle and H. B. Fell, vol. 2, pp. 178-204. North-Holland Publishing Co., Amsterdam and London.

Axel, R., Schlom, J., and Spiegelman, S. (1972). Presence in human breast cancer of RNA homologous to mouse mammary tumour virus RNA. Nature (Lond.), 235, 32-36.

Chiarugi, V. P. (1969). Changes of nuclear RNA in hepatomas as revealed by RNA/DNA hybridization. Biochim. biophys. Acta (Amst.), 179, 129-135.

Church, R. B., Luther, S. W., and McCarthy, B. J. (1969). RNA synthesis in taper hepatoma and mouse-liver cells. Biochim. biophys. Acta (Amst.), 190, 30-37.

Drews, J., Brawerman, G., and Morris, H. P. (1968). Nucleotide sequence homologies in nuclear and cytoplasmic ribonucleicacid from rat liver and hepatomas. Europ. J. Biochem., 3, 284-292.

Dyson, B. C. (1959). Cushing's disease: report of a case associated with carcinoma of the thyroid gland and cryptococcosis. New Engl. J. Med., 261, 169-172.

Friend, C., Scher, W., Holland, J. G., and Sato, T. (1971), Hemoglobin synthesis in murine virus-induced leukemic cells in vitro: stimulation of erythroid differentiation by dimethyl sulfoxide. Proc. nat. Acad. Sci. (Wash.), 68, 378-382.

Goodall, C. M. (1969). On para-endocrine cancer syndromes. Int. J. Cancer, 4, 1-13.

Greenstein, J. P. (1954). Biochemistry of Cancer, 2nd ed. Academic Press, New York.

Hadorn, E. (1965). Problems of determination and transdetermination. Brookhaven Symposium Biol., 18, 148-161.

Hehlmann, R., Kufe, D., and Spiegelman, S. (1972a). Viral-related RNA in Hodgkins' disease and other human lymphomas. Proc. nat. Acad. Sci. (Wash.), 69, 1727-1731.
Hehlmann, R., Kufe, D., and Spiegelman, S. (1972b). RNA in human leukemic cells related to the RNA of a mouse leukemia virus. Proc. nat. Acad. Sci. (Wash.), 69, 435-439.

Huebner, R. J., and Todaro, G. J. (1969). Oncogenes of RNA tumor viruses as determinants of cancer. Proc. nat. Acad. Sci. (Wash.), 64, 1087-1094.

Jacob, S. T., and Busch, H. (1967). Template activity of nuclear RNA fractions of the Walker tumor. Biochim. biophys. Acta (Amst.), 138, 249-257.

Kufe, D., Hehlmann, R., and Spiegelman, S. (1972). Human sarcomas contain RNA related to the RNA of a mouse leukemia virus. Science, 175, 182-185.

Laurence, D. J. R., and Neville, A. M. (1972). Foetal antigens and their role in the diagnosis and clinical management of human neoplasms: a review. Brit. J. Cancer, 26, 335-355.

Liddle, G. W. (1960). Tests of pituitary-adrenal suppressability in the diagnosis of Cushing's syndrome. J. clin. Endocr., 20, $1539-1560$.

Magee, P. N., and Barnes, J. M. (1967). Carcinogenic nitroso compounds. Advanc. Cancer Res., 10, 163-246.

Mendecki, J., Minc, B., and Chorąży, M. (1969). Differences in RNA from rat liver and hepatoma revealed by DNA-RNA hybridization. Biochem. biophys. Res. Commun., 36, 494-501.

Neiman, P. E., and Henry, P. H. (1969). Ribonucleic acid-deoxyribonucleic acid hybridization and hybridization-competition studies of the rapidly labeled ribonucleic acid from normal and chronic lymphocytic leukemic lymphocytes. Biochemistry, 8, 275-282.

Paul, J., and Gilmour, R. S. (1966). Template activity of DNA is restricted in chromatin. J. molec. Biol., 16, 242-244.

Paul, J., and Gilmour, R. S. (1968). Organ-specific restriction of transcription in mammalian chromatin. J. molec. Biol., 34, 305-316.

Pitot, H. C., Peraino, C., Morse, P. A. V., Jr., and Potter, V. R. (1964). Hepatomas in tissue culture compared with adapting liver in vivo. Nat. Cancer Inst. Monogr., 13, 229-245.

Potter, V. R. (1958). The biochemical approach to the cancer problem. Fed. Proc., 17, 691-697.

Riggs, B. L., and Sprague, R. G. (1961). Association of Cushing's syndrome and neoplastic disease: observations in 232 cases of Cushing's syndrome and review of the literature. Arch. intern. Med., 108, 841-849.

Spiegelman, S., Axel, R., and Schlom, J. (1972). Virus-related RNA in human and mouse mammary tumors. $J$. nat. Cancer. Inst., 48, 1205-1211.

Turkington, R. W., and Self, D. J. (1970). New species of hybridizable nuclear RNA in breast cancer cells. Cancer Res., 30, 1833-1840.

Winocour, E. (1971). The investigation of oncogenic viral genomes in transformed cells by nucleic acid hybridization. Advanc. Cancer Res., 14, 37-70. 